\title{
Hip osteoarthritis signs and symptoms are associated with increased fall risk among community-dwelling older adults with chronic low back pain: a prospective study
}

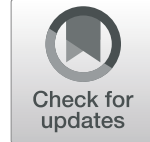

Patrick J. Knox ${ }^{1}$, Peter C. Coyle ${ }^{1}$, Jenifer M. Pugliese ${ }^{1}$, Ryan T. Pohlig ${ }^{2,3}$, Jaclyn M. Sions ${ }^{1}$ and Gregory E. Hicks ${ }^{1 *}$ (D)

\begin{abstract}
Background: Older adults with concurrent low back and hip pain are predisposed to reductions in physical performance and health-related quality of life. Yet no study to date has assessed whether or not coexisting hip impairments increase fall risk in older adults with chronic low back pain (CLBP). The objective of this study was to determine if hip osteoarthritis $(\mathrm{OA})$ signs and symptoms per American College of Rheumatology (ACR) criteria are associated with fall risk over a 1-year span.
\end{abstract}

Methods: Falls were prospectively monitored for 1 year via fall calendars. Age, sex, body mass index (BMI), anxiolytic use, balance confidence, LBP-related disability, and prior fall history were identified as covariates. Hip pain, pain with hip internal rotation (IR), hip $I R$ range of motion $(R O M) \geq 15^{\circ}$, and morning stiffness lasting $\leq 60$ min were evaluated at baseline and summed to represent hip OA impairment burden. A generalized linear model with a Poisson distribution and log link function assessed the association between ACR criteria and fall risk beyond established covariates. As a secondary analysis, binary logistic regression assessed ACR criteria and the odds of falling two or more times within a year.

Results: Data from two-hundred and ten participants were analyzed. Hip OA signs and symptoms were present in $97.1 \%$ of the participants, and hip OA impairment burden was significantly greater $(p<0.050)$ in participants who fell $\geq 2$ times compared to single and non-fallers. Higher hip OA impairment burden was associated with significantly increased fall risk ( $p=0.001$, risk ratio $=1.23,95 \% \mathrm{Cl} 1.09-1.38)$ and odds of falling multiple times $(p<$ 0.05 , odds ratio $=1.41,95 \% \mathrm{Cl} 1.01-1.95)$ after adjustment for covariates.

Conclusions: Older adults with CLBP and concomitant hip impairments are an at-risk group for falling. Healthcare professionals should employ falls screening and preventive measures to avoid negative sequelae in this vulnerable population.

Keywords: Accidental falls, Aged, Low back pain, Osteoarthritis, Risk factors

\footnotetext{
*Correspondence: ghicks@udel.edu

'Department of Physical Therapy, University of Delaware, 540 S. College Ave, Newark, DE 19713, USA

Full list of author information is available at the end of the article
}

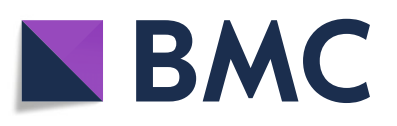

(- The Author(s). 2021 Open Access This article is licensed under a Creative Commons Attribution 4.0 International License, which permits use, sharing, adaptation, distribution and reproduction in any medium or format, as long as you give appropriate credit to the original author(s) and the source, provide a link to the Creative Commons licence, and indicate if changes were made. The images or other third party material in this article are included in the article's Creative Commons licence, unless indicated otherwise in a credit line to the material. If material is not included in the article's Creative Commons licence and your intended use is not permitted by statutory regulation or exceeds the permitted use, you will need to obtain permission directly from the copyright holder. To view a copy of this licence, visit http://creativecommons.org/licenses/by/4.0/ The Creative Commons Public Domain Dedication waiver (http://creativecommons.org/publicdomain/zero/1.0/) applies to the data made available in this article, unless otherwise stated in a credit line to the data. 


\section{Background}

In the USA, low back pain (LBP) is the most frequently reported musculoskeletal complaint among older adults [1]. According to Medicare data from 1991 to 2002, there was a $131.7 \%$ increase in LBP patients and a $387.2 \%$ increase in LBP-related expenditures, suggesting that LBP is becoming more prevalent and costly among older adults [2]. Apparent increases in LBP prevalence among this age group are especially problematic because this clinical population is susceptible to steep functional decline $[3,4]$. Consistent patient and public health burdens indicate that existing LBP management strategies are lacking; these concerns extend to chronic LBP (CLBP), which is understudied and poorly understood in older adults $[5,6]$. Management of CLBP in older adults may be complicated by underlying influences from coexisting pain conditions $[6,7]$; there is a need to explore how coexisting pain conditions, particularly hip impairments, may affect health outcomes in this clinical population.

Recent evidence suggests that coexisting hip impairments are more prevalent in and detrimental to older adults with CLBP. Hicks et al. [7] demonstrated that hip osteoarthritis (OA) signs and symptoms, as defined by American College of Rheumatology (ACR) criteria [8], are associated with poorer performance on physical function tests beyond the influence of CLBP alone; they are also associated with higher disability and reduced health-related quality of life in this patient population [9]. Rundell et al. [10] corroborate this association, as they report that older adults with coexisting hip OA and back pain had worse disability health-related quality of life than older adults with LBP alone. These findings are consistent with prior evidence on more distal health outcomes in older adults; hip OA has been established as a risk factor for falling and is associated with elevated annual fall prevalence compared to national estimates of falls in older adults $[11,12]$.

Falls are both costly and disabling for older adults [13], and individuals who fall two or more times within a year, or multiple fallers, are at greater risk of mobility decline, activities of daily living decline, hospitalization, institutionalization, and death when compared to people who fall less than two timer per year, or non-multiple fallers [14]. Hip pain, LBP, and multisite joint pain have been shown to individually increase fall risk [15-18]. This evidence, in conjunction with the known adverse effects of hip OA on functional decline and fall risk $[7,11,12]$, suggests that hip OA signs and symptoms may further predispose older adults with CLBP to falling. To alleviate patient and public health burdens, it is imperative to investigate if coexisting hip OA signs and symptoms contribute to fall risk in older adults with CLBP.

To our knowledge, no study has assessed the extent to which hip joint symptoms affect risk of falls in older adults with a primary complaint of CLBP. The purpose of this study was to determine if hip OA signs and symptoms were associated with falls in older adults with CLBP. We hypothesized that an increased number of hip OA signs and symptoms would correspond to elevated fall risk over 1-year follow-up.

\section{Methods}

\section{Study overview}

This is a secondary analysis of data from a 12-month prospective study that included 250 generally healthy community-dwelling older adults between the ages of 60 and 85 years with CLBP who could ambulate independently with or without a single point cane (Hicks GE, Pohlig RT, Coyle PC, Sions JM, Weiner DK, Pugliese JM, et al.: Classification of geriatric low back pain based on hip characteristics with a 12-month longitudinal exploration of clinical outcomes: Findings from Delaware Spine Studies, submitted). CLBP status was characterized by research standards for this patient population [19]: LBP intensity $\geq 3 / 10$, LBP frequency on four or more days of the week, LBP duration $\geq 3$ months, and LBP that negatively impacts daily function. Participants were ineligible if they had lower extremity pain that was greater in intensity than their LBP, non-mechanical spinal conditions such as ankylosing spondylitis, current fractures in the back or hip, a progressive neurological diagnosis, or a terminal illness. Data for the parent study was collected in-person at baseline as well as 3 months, 6 months, and 12 months post-baseline in the University of Delaware's Clinical Research Evaluation Laboratory; for this investigation, baseline clinical evaluation data and falls data throughout a12-month follow-up were utilized. The study was approved by the University of Delaware's Institutional Review Board and was conducted in accordance with the Declaration of Helsinki. All participants signed an informed consent form.

\section{Baseline characteristics}

Participants reported their age, sex, race, and fall history from the year prior to baseline. Height and weight were measured in centimeters $(\mathrm{cm})$ and kilograms $(\mathrm{kg})$, respectively, and converted to body mass index (BMI). Separate composite pain measures were created for the both hip and low back regions by averaging three pain intensity ratings for each area $(0=$ none, $10=$ worst pain imaginable): highest and lowest pain over the last $24 \mathrm{~h}$, and current pain at the time of baseline evaluation. The Activities-Specific Balance Confidence Scale (ABC-16) and Quebec Back Pain Disability Scale (QBPDS) are reliable and valid measures that were completed at baseline to obtain self-perceived balance confidence [20] and LBP-related disability [21], respectively. A detailed list of brand and generic medication names was used to obtain 
medication usage; medications from the benzodiazepine drug class were grouped as "anxiolytic medications" and summed together. Balance confidence [22, 23], LBPrelated disability [24], and benzodiazepine usage [25] have previously been associated with elevated fall risk in older adults; as such, they were identified as covariates.

\section{Hip OA impairment burden}

Hip OA signs and symptoms were assessed at baseline using the ACR guidelines: presence of hip pain, hip internal rotation (IR) range of motion $(\mathrm{ROM}) \geq 15^{\circ}$, pain exacerbation with passive hip IR ROM, and morning stiffness lasting $\leq 60 \mathrm{~min}$ upon waking [8]; this subset of ACR criteria has been found to be prevalent among older adults with CLBP [7]. Hip pain was ascertained by asking participants, "Do you have pain in your groin/ buttock/thigh?", with possible responses of "yes" or "no". Morning stiffness was determined by asking participants, "Do you have morning stiffness in your hip?"; if participants answered "yes", they were queried, "Does it last less than or equal to 60 minutes?". Both hip IR variables were collected during a clinical examination of passive ROM; the magnitude of ROM was measured in prone with an inclinometer [26, 27], while pain exacerbation during examination was defined as the onset of "groin, lateral thigh, or buttock pain". The presence of hip pain and morning stiffness upon waking were coded as dichotomous variables $(0=$ no, $1=$ yes $)$, whereas hip IR range of motion and pain variables were collected for both hips and coded accordingly $(0=$ absent, $1=$ unilateral, 2 =bilateral). ACR criteria were measured and summed to create a burden variable (hereafter referred to as hip OA impairment burden) with a maximum possible score of 6 , with more criteria indicating a higher likelihood of hip OA [8]. All participants were $>50$ years old, so that criterion was not included in the calculation.

\section{Falls outcome}

A fall was operationally defined as any accidental or unintentional event in which contact was made with a lower surface or the ground [28]. Fall incidence was monitored via monthly fall calendars, which are the preferred method for prospective studies [29, 30]. At baseline, 3-month, and 6-month visits, participants were provided with a sufficient number of falls calendars and pre-stamped envelopes to account for time between inperson visits; participants were asked to mail their falls calendars to laboratory staff on a monthly basis. To prevent lapses in falls data, participants also received monthly follow-up phone calls to encourage timely return of fall calendars and to document any unreported falls that occurred in the previous month. On the fall calendars, participants were instructed to record an " $\mathrm{F}$ " on each day a fall occurred and an "N" on each day a fall did not occur. Outstanding calendars from prior followup time points were collected at the 12-month assessment visit. Falls were summed across the participants' monthly calendars and follow-up calls. In the event that both the fall calendars were missing and the phone screens were incomplete, the falls data for that participant was excluded. If participants withdrew or died before study completion, that data was excluded as well. This adjudication of fall counts was completed prior to processing of all baseline data.

\section{Data analysis}

All analyses were completed on IBM SPSS Statistics versions 24 and 25 (SPSS, Inc. Armonk, NY). Only participants with complete falls data over 12 months were included ( $n=212$ of 250 ); two outliers in fall counts were removed from the sample based on the distribution of reported falls, leaving 210 for analysis (Fig. 1). Skewness and kurtosis were assessed for continuous variables to confirm compliance with parametric assumptions. Differences between included and excluded participants were assessed via chi-square and independent $t$-tests for nominal and continuous variables, respectively, and Mann-Whitney $U$ tests for ordinal or non-normal variables. The prevalence of hip OA impairment burden in the study sample was assessed with frequencies. Differences in hip OA impairment burden between non-multiple and multiple fallers were assessed with Mann-Whitney $U$ tests. The relationship between the number of falls and hip OA impairment burden was modeled via a Generalized Linear Model with Poisson distribution and log link function. To further assess if hip OA impairment burden was associated with the clinically relevant outcome of falling two or more times within a year [14], a binary logistic regression was performed as a secondary analysis. Both models adjusted for seven covariates: sex, age, BMI, anxiolytic use, balance confidence, LBP-related disability, and prior fall history. Bivariate correlation matrices were utilized to assess for multicollinearity among the covariates and hip OA impairment burden; cutoffs for bivariate correlation values were $<0.80$. Significance was set to $p<0.05$ for all analyses.

\section{Results}

Excluded participants had significantly higher average LBP intensity and LBP-related disability compared to included participants, who had mild to moderate LBP intensity and LBP-related disability ratings (see Table 1 ). On average, included participants had moderate to high levels of balance confidence [31]. Over a 12-month span, 89 participants (42.4\%) fell a total of 219 times. Among participants who fell, 50 (56.2\%) fell more than once for a median of two and interquartile range of two (range 


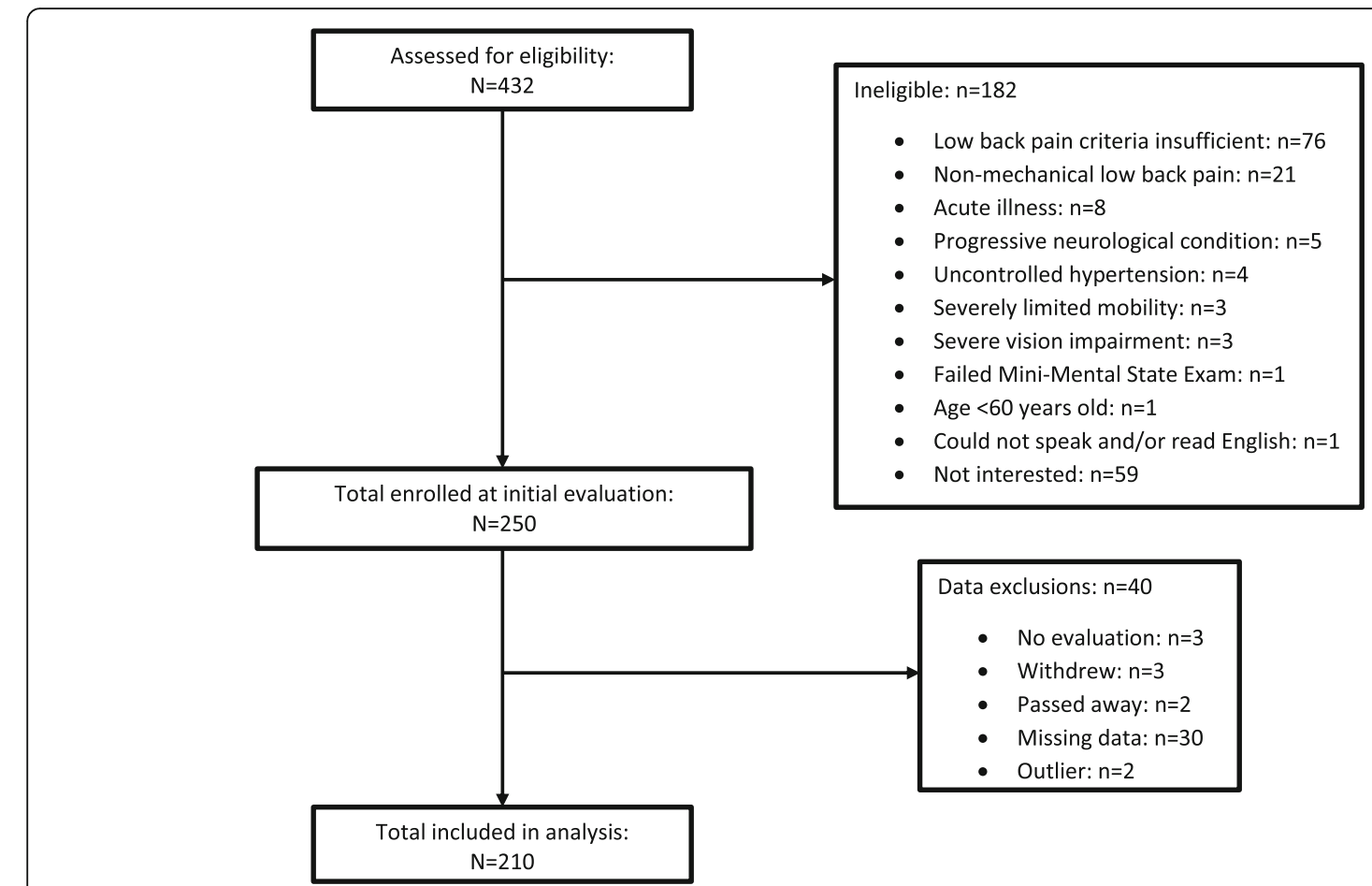

Fig. 1 Study flow and participant inclusion process diagram

from 1 to 12). Multicollinearity was not present among covariates and hip OA impairment burden (all $r<0.63$ ).

One or more hip OA signs and symptoms were present in $97.1 \%$ of our study population (Fig. 2). Hip IR ROM variables were the most common criteria present, with positive measurements in $>80 \%$ of participants; presence of hip pain (68.6\%) and morning stiffness upon waking $(43.3 \%)$ were also prevalent, while pain with passive hip IR ROM was less common $(<15 \%)$. Compared to non-multiple fallers, multiple fallers had significantly greater hip OA impairment burden $(p<0.05)$.

Associated relative risks (RR) and $95 \%$ confidence intervals $(\mathrm{CI})$ are presented in Table 2 . The overall generalized linear model was statistically significant $(p<0.005)$. After adjusting for covariates, hip OA impairment burden was significantly associated with fall risk $(p=0.001, \mathrm{RR}=1.23$, 95\% CI: $1.09-1.38$ ); the RR corresponds to a $23 \%$ increase in the risk of falling for each additional ACR criterion

Table 1 Included versus excluded participant characteristics

\begin{tabular}{lll}
\hline & Included $(\boldsymbol{N}=\mathbf{2 1 0})$ & Excluded $(\boldsymbol{N}=\mathbf{4 0})$ \\
\hline Sex: female & Mean \pm SD or $\boldsymbol{N}(\mathbf{\%})$ & $22(55.0 \%)$ \\
Race: white & $106(50.5 \%)$ & $32(80.0 \%)$ \\
Age (years) & $181(86.2 \%)$ & $68.97 \pm 7.38$ \\
BMI (kilograms/meters ${ }^{2}$ ) & $69.85 \pm 6.74$ & $29.76 \pm 6.42$ \\
Average LBP intensity (0-10) & $29.37 \pm 5.57$ & $3.68 \pm 1.67^{*}$ \\
Average hip pain intensity (0-10) & $2.96 \pm 1.40$ & $2.25 \pm 1.89$ \\
QBPDS (0-100) & $1.72 \pm 1.72$ & $34.66 \pm 17.36^{*}$ \\
ABC-16 (0-100) & $27.08 \pm 16.21$ & $73.83 \pm 22.32$ \\
Anxiolytics & $80.85 \pm 18.19$ & $0.13 \pm 0.33$ \\
Hip OA impairment burden (0-6) & $0.08 \pm 0.28$ & $3.15 \pm 1.33+$ \\
Prior falls & $3.07 \pm 1.29$ & $1.08 \pm 2.34 \dagger$ \\
\hline
\end{tabular}

Note: Categorical values are presented as total number (\% of sample), while continuous values are presented as mean ( \pm SD)

Abbreviations: BMI, body mass index; $L B P$, low back pain; QBPDS, Quebec Back Pain Disability Scale; ABC-16, Activities-Specific Balance Confidence Scale ${ }^{*} p<0.05 ; \dagger=$ distributions were non-normal, reported $p$ value is from Mann-Whitney test 


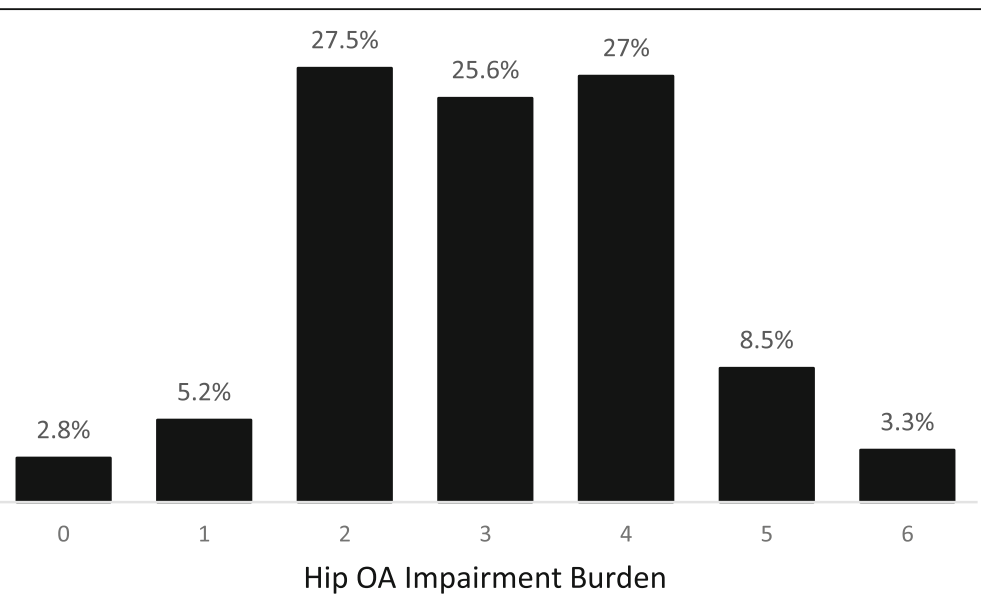

Fig. 2 Frequency distribution of hip OA impairment burden

present. Hip OA impairment burden was also associated with significantly increased odds of falling two or more times after adjusting for the covariates $(p<0.05$, odds ratio $=1.41,95 \%$ CI 1.01-1.95), such that a 1-unit increase in hip OA impairment burden corresponds to a $41 \%$ increase in the odds of falling multiple times within a year.

\section{Discussion}

Fall incidence over a 12-month period was considerably higher in this cohort of older adults with chronic low back pain (42.4\%) compared to national estimates of $28.7 \%$ for this age group [13]. Hip OA signs and symptoms were highly prevalent and independent risk factors for falls in this cohort, such that each increase in hip OA impairment burden was associated with a successively greater risk of falling. Furthermore, greater hip OA impairment burden was associated with falling two or more times throughout study follow-up, which contextualizes the risk that is posed by elevated hip OA impairment burden in older adults. Our hypotheses were therefore supported. These findings are novel, as

Table 2 Poisson regression model risk ratios

\begin{tabular}{lll}
\hline Variable & RR $(\mathbf{9 5 \%}$ Cl) & $\boldsymbol{p}$ value \\
\hline Age & $1.01(0.99-1.04)$ & 0.190 \\
Sex (ref = female) & $1.04(0.76-1.42)$ & 0.815 \\
BMI & $1.00(0.98-1.03)$ & 0.839 \\
Anxiolytics & $2.39(1.70-3.36)$ & $<0.001^{*}$ \\
ABC-16 & $1.00(0.99-1.01)$ & 0.717 \\
QBPDS & $0.99(0.98-1.00)$ & 0.148 \\
Prior falls & $1.08(1.05-1.11)$ & $<0.001^{*}$ \\
Hip OA impairment burden & $1.23(1.09-1.38)$ & $0.001^{*}$ \\
\hline Abbreviations: $R R$, risk ratio; Cl, confidence interval; BMI, body mass index; \\
QBPDS, Quebec Back Pain Disability Scale; ABC-16, Activities-Specific Balance \\
Confidence Scale \\
* $p<0.05$
\end{tabular}

no study to date has investigated the additive effect of hip OA signs and symptoms on fall risk among older adults with CLBP.

Our findings are consistent with prior evidence that ACR criteria for hip OA are common in older adults with CLBP [7], and add to the body of literature that links hip OA signs and symptoms to greater fall risk in older adults [11, 12, 18]. Given that the intent of our study was to preliminarily assess if ACR hip OA criteria independently increased fall risk in older adults with CLBP, we cannot speculate on which criteria are driving this relationship. Sturnieks et al. [12] established that arthritis group membership, which significantly increased fall risk in older adults, was determined by neuromuscular characteristics more so than pain via discriminant function analysis. Munch et al. [18] demonstrated that self-reported hip pain was a risk factor for falls in older men independent of covariates, including osteoarthritis. Based on prior evidence, it is reasonable to infer that both rheumatologic [12] and nociceptive pain [18] characteristics contribute to the deleterious effects of hip OA signs and symptoms. Future investigations should aim to delineate which facets of hip OA signs and symptoms are contributing most to poor health outcomes in older adults with and without coexisting pain conditions.

Fall prevalence data from our study suggests that CLBP may increase fall risk. This finding aligns with work from Marshall et al. [16, 17], wherein back pain and LBP independently elevated fall risk in a subsample of the Osteoporotic Fractures in Men Study (MrOS) cohort and women from the Study of Osteoporotic Fractures (SOF) cohort, respectively. The cumulative weight of prior evidence plus our findings suggests that hip impairments compound fall risk in older adults; those with coexisting CLBP are at even further risk of falling. 
Recent findings from Hicks et al. [7] showed that performance tests predictive of mobility decline (i.e., repeated chair rise and stair-climbing tests) were significantly worse among CLBP participants with coexisting hip impairments. Poorer performance on mobility tests increases an older adult's risk for multiple falls [32]. Mobility decline is part of the pathway from health to adverse health outcomes such as falling; our results, in conjunction with prior evidence of susceptibility to mobility decline $[7,14,32]$, establish that coexisting hip impairments increase fall risk and overall vulnerability of older adults with CLBP.

Our findings of increased fall risk secondary to higher hip OA impairment burden partially diverges with prior evidence. Leveille et al. [15] reported that back pain in combination with other pain sites does not affect fall risk in older adults. In the MrOS and SOF cohorts, hip pain prevalence incrementally increased with back pain and LBP severity; however, hip pain was not an effect modifier of the relationship between back pain and falls $[16,17]$. It is possible that the results of these studies differ from our findings due to differences in study populations and methods of ascertaining pain. Clinical hip OA signs and symptoms may capture information that is unique from dichotomous classifications of hip pain, and as such may differentially affect prospective fall risk. Further, our criteria for CLBP are representative of a well-defined clinical population rather than a spectrum of LBP characteristics; risks and health outcomes for CLBP are distinct from other areas of back pain (i.e., thoracic) and non-chronic LBP.

The findings of the present study have clear clinical implications for older adults with CLBP. When combining the elevated fall risk from CLBP alone with the additional fall risk due to concomitant hip impairments, it becomes clear that healthcare professionals should screen older patients with CLBP for hip impairments as well as overall fall risk, and appropriately intervene. While further evidence is required, it seems that improving the symptoms associated with hip impairments may benefit older adults by reducing both fall risk and functional limitations. Therefore, plans of care with targeted treatment strategies should be considered for this important population.

This study has considerable strengths, including the sample size, use of fall calendars [29], adjustment for an array of well-reported risk factors, and a robust regression model. However, the results should be viewed in light of some limitations. Observational studies preclude the ability to make causative claims. Additionally, the studied cohort had mild self-reported back and hip pain and moderate LBP-related disability, which may limit generalizability to populations with more severe pain or disability. Further, given that excluded participants had significantly higher average LBP ratings and QBPDS values, our reported association between hip-related burden and risk of multiple falls may be underestimated. Finally, cutoffs for multicollinearity diagnostics are not universally agreed upon and may not entirely detect instances of multicollinearity [33], so the results should be interpreted with caution.

\section{Conclusion}

Higher burden of hip OA signs and symptoms as identified by ACR criteria independently increased the risk of falls among older adults with CLBP. These results are an extension of prior evidence; LBP and hip pain have previously been established as independent risk factors for falls, and together are associated with reduced performance in repeated chair rise and stair-climbing tasks. The findings suggest that hip pain should be comprehensively evaluated in older adults who present with CLBP. Given that CLBP and concomitant hip OA signs and symptoms predispose older adults to falls, preventative intervention strategies should be considered in plans of care. Future studies should address how particular intervention strategies, such as hip-focused treatment, impact mobility and fall risk.

\begin{abstract}
Abbreviations
LBP: Low back pain; CLBP: Chronic low back pain; ACR: American College of Rheumatology; OA: Osteoarthritis; BMI: Body mass index; IR: Internal rotation; ROM: Range of motion; ABC-16: Activities-Specific Balance Confidence Scale; QBPDS: Quebec Back Pain Disability Scale; MrOS: Osteoporotic Fractures in Men Study; SOF: Study of Osteoporotic Fractures; RR: Risk ratio; OR: Odds ratio
\end{abstract}

\section{Acknowledgements}

Not applicable.

\section{Authors' contributions}

PK contributed to study conception and design, data processing, secondary data analysis, and all stages of manuscript development. PC assisted with study design, data acquisition, data analysis and interpretation, and manuscript revision. JP contributed to both data acquisition and processing, as well as manuscript preparation and revision. RP assisted with study design and data processing, conducted and interpreted the primary data analysis, and revised the manuscript. JS assisted with study design, coordinated the study wherein data was acquired, and revised the manuscript. GH is the principal investigator and study guarantor and contributed to all facets of this project: study conception and design, data processing, data analysis and interpretation, and manuscript revision. All authors read and approved the final manuscript.

\section{Funding}

This work was supported by Award Number R01AG0412202 from the National Institute on Aging of the National Institutes of Health. Manuscript preparation was supported, in part, by the Eunice Kennedy Shriver National Institute of Child Health and Human Development of the National Institutes of Health (grant number T32-HD007490). The content is solely the responsibility of the authors and does not necessarily represent the official views of the National Institutes of Health.

\section{Availability of data and materials}

The data analyzed during this study are presented in this article. Other data for the current study are not publicly available in order to maintain the confidentiality and anonymity of study participants; data may be available from the corresponding author upon reasonable request. 


\section{Declarations}

\section{Ethics approval and consent to participate}

This study was approved by the Institutional Review Board at the University of Delaware (Newark, DE). All participants signed informed consent forms prior to study enrollment.

\section{Consent for publication}

Not applicable.

\section{Competing interests}

The authors declare that they have no competing interests.

\section{Author details}

'Department of Physical Therapy, University of Delaware, 540 S. College Ave, Newark, DE 19713, USA. ${ }^{2}$ Department of Epidemiology, University of Delaware, Newark, DE, USA. ${ }^{3}$ Biostatistics Core, University of Delaware, Newark, DE, USA.

\section{Received: 31 August 2020 Accepted: 18 February 2021}

\section{Published online: 03 March 2021}

\section{References}

1. Bressler HB, Keyes WJ, Rochon PA, Badley E. The prevalence of low back pain in the elderly. A systematic review of the literature. Spine (Phila Pa 1976). 1999:24(17):1813-9.

2. Weiner DK, Kim YS, Bonino P, Wang T. Low back pain in older adults: are we utilizing healthcare resources wisely? Pain Med. 2006;7(2):143-50.

3. Reid MC, Williams CS, Gill TM. Back pain and decline in lower extremity physical function among community-dwelling older persons. J Gerontol A Biol Sci Med Sci. 2005;60(6):793-7.

4. Hicks GE, Simonsick EM, Harris TB, Newman AB, Weiner DK, Nevitt MA, et al. Trunk muscle composition as a predictor of reduced functional capacity in the health, aging and body composition study: the moderating role of back pain. J Gerontol A Biol Sci Med Sci. 2005;60(11):1420-4.

5. Paeck T, Ferreira ML, Sun C, Lin CW, Tiedemann A, Maher CG. Are older adults missing from low back pain clinical trials? A systematic review and meta-analysis. Arthritis Care Res (Hoboken). 2014;66(8):1220-6.

6. Simon $C B$, Hicks GE. Paradigm shift in geriatric low back pain management: integrating influences, experiences, and consequences. Phys Ther. 2018; 98(5):434-46.

7. Hicks GE, Sions JM, Velasco TO. Hip symptoms, physical performance, and health status in older adults with chronic low back pain: a preliminary investigation. Arch Phys Med Rehabil. 2018;99(7):1273-8.

8. Altman R, Alarcón G, Appelrouth D, Bloch D, Borenstein D, Brandt K, et al. The American College of Rheumatology criteria for the classification and reporting of osteoarthritis of the hip. Arthritis Rheum. 1991;34(5):505-14.

9. Hicks $G$, Sions J, Velasco T. Hip symptoms contribute to low back painrelated disability in older adults with a primary complaint of low back pain: the Delaware spine studies. Osteoarthr Cartil. 2016;24:S439.

10. Rundell SD, Goode AP, Suri P, Heagerty PJ, Comstock BA, Friedly JL, et al. Effect of comorbid knee and hip osteoarthritis on longitudinal clinical and health care use outcomes in older adults with new visits for Back pain. Arch Phys Med Rehabil. 2017;98(1):43-50.

11. Arnold CM, Faulkner RA. The history of falls and the association of the timed up and go test to falls and near-falls in older adults with hip osteoarthritis. BMC Geriatr. 2007;7:17.

12. Sturnieks DL, Tiedemann A, Chapman K, Munro B, Murray SM, Lord SR. Physiological risk factors for falls in older people with lower limb arthritis. J Rheumatol. 2004;31(11):2272-9.

13. Bergen $G$, Stevens MR, Burns ER. Falls and fall injuries among adults aged $\geq 65$ years - United States, 2014. MMWR Morb Mortal Wkly Rep. 2016:65(37):993-8.

14. Wolinsky FD, Johnson RJ, Fitzgerald JF. Falling, health status, and the use of health services by older adults. A prospective study. Med Care. 1992;30(7): 587-97.

15. Leveille SG, Jones RN, Kiely DK, Hausdorff JM, Shmerling RH, Guralnik JM, et al. Chronic musculoskeletal pain and the occurrence of falls in an older population. Jama. 2009;302(20):2214-21.

16. Marshall LM, Litwack-Harrison S, Cawthon PM, Kado DM, Deyo RA Makris UE, et al. A prospective study of back pain and risk of falls among older community-dwelling women. J Gerontol A Biol Sci Med Sci. 2016:71(9):1177-83.

17. Marshall LM, Litwack-Harrison S, Makris UE, Kado DM, Cawthon PM, Deyo RA, et al. A prospective study of back pain and risk of falls among older community-dwelling men. J Gerontol A Biol Sci Med Sci. 2017;72(9):1264-9.

18. Munch T, Harrison SL, Barrett-Connor E, Lane NE, Nevitt MC, Schousboe JT, et al. Pain and falls and fractures in community-dwelling older men. Age Ageing. 2015;44(6):973-9.

19. Deyo RA, Dworkin SF, Amtmann D, Andersson G, Borenstein D, Carragee E, et al. Report of the NIH Task Force on research standards for chronic low back pain. J Pain. 2014;15(6):569-85.

20. Powell LE, Myers AM. The Activities-specific Balance Confidence (ABC) Scale. J Gerontol A Biol Sci Med Sci. 1995:50a(1):M28-34.

21. Hicks GE, Manal TJ. Psychometric properties of commonly used low back disability questionnaires: are they useful for older adults with low back pain? Pain Med. 2009;10(1):85-94

22. Landers MR, Oscar S, Sasaoka J, Vaughn K. Balance confidence and fear of falling avoidance behavior are most predictive of falling in older adults: prospective analysis. Phys Ther. 2016;96(4):433-42.

23. Cleary K, Skornyakov E. Predicting falls in community dwelling older adults using the activities-specific balance confidence scale. Arch Gerontol Geriatr. 2017;72:142-5.

24. Kimachi K, Kimachi M, Takegami M, Ono R, Yamazaki S, Goto Y, et al. Level of low back pain-related disability is associated with risk of subsequent falls in an older population: locomotive syndrome and health outcomes in Aizu cohort study (LOHAS). Pain Med. 2019;20(12):2377-84.

25. Richardson K, Bennett K, Kenny RA. Polypharmacy including falls riskincreasing medications and subsequent falls in community-dwelling middle-aged and older adults. Age Ageing. 2015;44(1):90-6.

26. Prather H, Harris-Hayes M, Hunt DM, Steger-May K, Mathew V, Clohisy JC. Reliability and agreement of hip range of motion and provocative physical examination tests in asymptomatic volunteers. Pm r. 2010;2(10):888-95.

27. Ellison JB, Rose SJ, Sahrmann SA. Patterns of hip rotation range of motion: a comparison between healthy subjects and patients with low back pain. Phys Ther. 1990:70(9):537-41.

28. World Health Organization. Falls Geneva, Switzerland: World Health Organization; January 16, 2018 [cited 2020 August 15]. Available from: https://www.who.int/news-room/fact-sheets/detail/falls.

29. Hannan MT, Gagnon MM, Aneja J, Jones RN, Cupples LA, Lipsitz LA, et al. Optimizing the tracking of falls in studies of older participants: comparison of quarterly telephone recall with monthly falls calendars in the MOBILIZE Boston Study. Am J Epidemiol. 2010;171(9):1031-6.

30. Freiberger $E$, de Vreede $P$. Falls recall-limitations of the most used inclusion criteria. Eur Rev Aging Phys Act. 2011:8(2):105-8.

31. Myers AM, Fletcher PC, Myers AH, Sherk W. Discriminative and evaluative properties of the activities-specific balance confidence (ABC) scale. J Gerontol A Biol Sci Med Sci. 1998;53(4):M287-94.

32. Tiedemann A, Shimada H, Sherrington C, Murray S, Lord S. The comparative ability of eight functional mobility tests for predicting falls in communitydwelling older people. Age Ageing. 2008:37(4):430-5.

33. Vatcheva KP, Lee M, McCormick JB, Rahbar MH. Multicollinearity in Regression Analyses Conducted in Epidemiologic Studies. Epidemiology (Sunnyvale). 2016;6(2):227.

\section{Publisher's Note}

Springer Nature remains neutral with regard to jurisdictional claims in published maps and institutional affiliations.

Ready to submit your research? Choose BMC and benefit from:

- fast, convenient online submission

- thorough peer review by experienced researchers in your field

- rapid publication on acceptance

- support for research data, including large and complex data types

- gold Open Access which fosters wider collaboration and increased citations

- maximum visibility for your research: over $100 \mathrm{M}$ website views per year

At BMC, research is always in progress.

Learn more biomedcentral.com/submissions 